SECTION 7. Mechanics and machine construction.

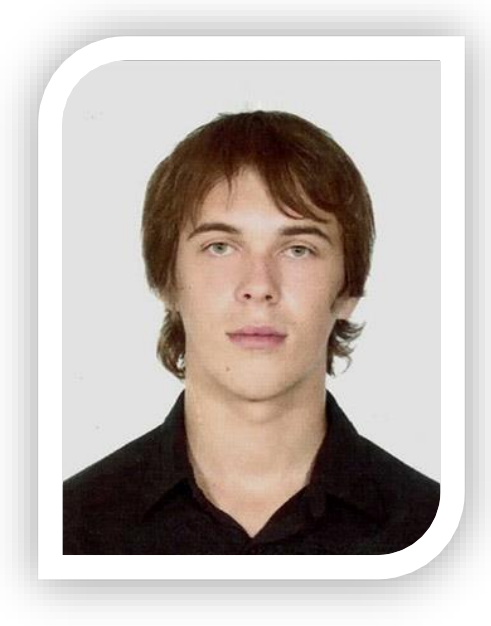

Semenchenko Nikolai Vladimirovich Student of the Department «Equipment and technology of machine-building production»» FSBEI HPE «Togliatti State University», Russia bonder64@mail.ru

Semenov Kirill Olegovich

Student of the Department «Equipment and technology of machine-building production» FSBEI HPE «Togliatti State University», Russia

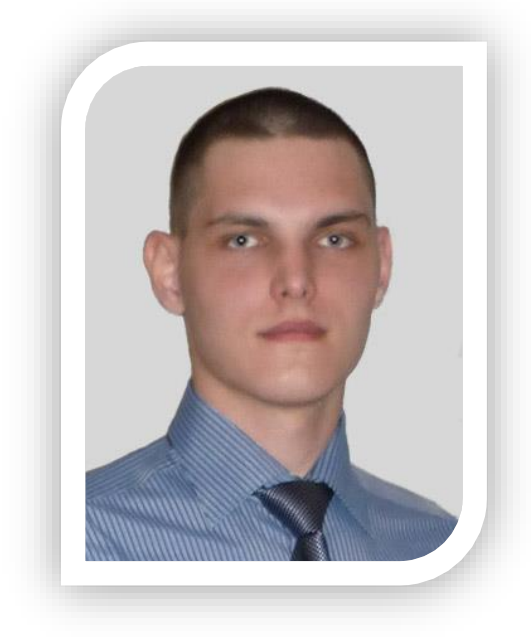

Emelianova Natalia Andreevna Student of the Department «Equipment and technology of machine-building production» FSBEI HPE «Togliatti State University», Russia

\title{
WEAR COMPENSATION OF WIRE TOOL DURING THE CONTROL OF CLADDING OPERATION
}

Abstract: This report describes the variants of deformational cladding operation of flat surfaces. The adaptive control method is proposed for compensation of wear influence of the flexible tool and maintenance of contact force at necessary level. The dependency relations for optimization of a choice of time of tool readjustment or replacement are given.

Key words: flexible tool; wire tool; cladding; stress; system control.

УДК 658.56:621.793

\section{КОМПЕНСАЦИЯ ИЗНОСА ВОРСА ПРОВОЛОЧНОГО ИНСТРУМЕНТА ПРИ УПРАВЛЕНИИ ПРОЦЕССОМ ПЛАКИРОВАНИЯ}

Аннотация: В данной статье рассмотрень варианты управления процессом деформационного плакирования плоских поверхностей. Предложен метод адаптивного управления для компенсаџии влияния износа гибкого инструмента и поддержания 
контактной силь на необходимом уровне. Приведень зависимости для оптимизаџии выбора времени переналадки или замень инструмента.

Ключевые слова: гибкий инструмент; проволочный инструмент; плакирование; напряжения; система управления.

Деформационное плакирование зарекомендовало себя как эффективный метод повышения долговечности деталей машин. В настоящее время происходит его внедрение в технологические процессы различного рода [1-3]. Однако постепенное разрушение инструмента во время обработки приводит к изменению толщины формируемого покрытия, что серьезно сказывается на эксплуатационных свойствах обработанных изделий и снижает экономическую эффективность метода в целом.

Исходя из практики применения, ресурс проволочного инструмента может составлять от $250 \ldots 280$ часов непрерывной работы при естественном износе до $8 . .10$ часов при усталостном характере разрушения ворса [4].

На стойкость гибкого инструмента серьезно влияют параметры процесса плакирования; их нерациональный выбор приводит к усталостному разрушению ворса [5]. Выбор же правильных параметров позволяет использовать металлическую щетку наиболее полно, подвергая ее только естественному износу (истиранию).

Данный фактор необходимо учитывать для поддержания качества получаемых покрытий. Рассмотрим его воздействие при плакировании плоской поверхности на режимах: $d_{6}=0,2 \mathrm{M \mu} ; r_{3}=100 \mathrm{M \mu} ; l_{И}=60 \mathrm{M \mu} ; D_{u}=320 \mathrm{MM} ; N=1,5 \mathrm{MM} ; V_{\text {ок }}=35 \mathrm{M} / \mathrm{c}$.

Истирание ворса определяем по данным работы, мм [6]:

$$
\Delta \ell=\mu \cdot \tau^{u з н}
$$

где эквивалентная скорость изнашивания, мм/час:

$$
\mu=\mu_{0} \cdot \frac{n_{3000}}{n_{u}},
$$

где $\mu_{0}$ - усредненная скорость изнашивания при 3000 об/мин $\left(\mu_{0}=0,07 \ldots 0,1 \mathrm{mм} /\right.$ час $)$, $n_{3000}$ - номинальная частота вращения щетки $\left(n_{3000}=3000\right.$ об/мин $)$,

$n_{w}$ - реальная частота вращения щетки;

$\tau^{u з н}$ - время истирания ворса $\left(\tau^{u з н}=250 \ldots 280\right.$ час) $)$.

Истирание ворса за время полной выработки щеткой своего ресурса, определенное по формуле (1), будет в районе 25 мм.

Если не учитывать истирание щетки и не корректировать натяг $N$ до необходимого уровня, то происходит его уменьшение, снижение силы $P$ в зоне контакта ворса с обрабатываемой поверхностью и напряжений $\sigma$ возникающих в металлической щетке (рис.1).

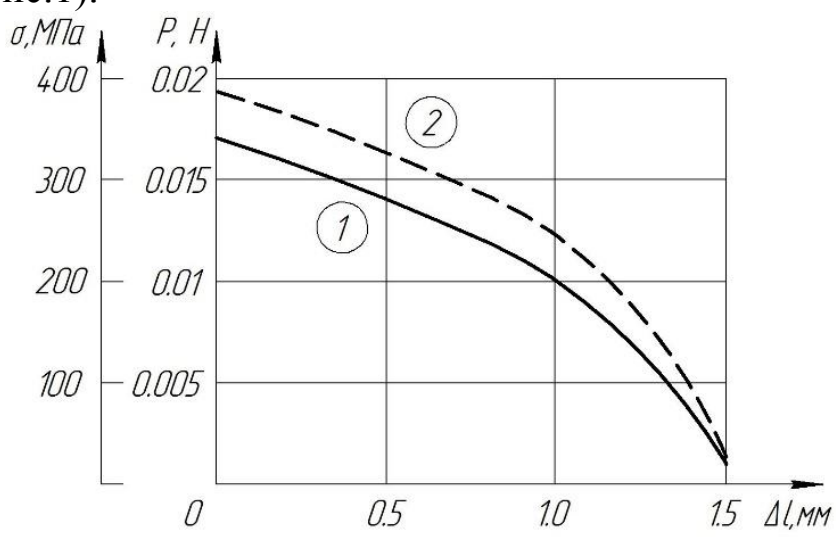

Рисунок 1 - Зависимость: 1 - максимального напряжения, 2 - максимальной силы от величины истирания ворса. 
По полученным зависимостям можно судить о постепенном уменьшении толщины наносимого покрытия, которая должна находиться в определенных пределах. К примеру, обрабатываемое изделие из серого чугуна (СЧ 21-40), а наносимое покрытие - оловянная бронза (БрОЦС 5-5-5); тогда, формируемая толщина покрытия должна быть в пределах 3,5-6 мкм [3]. При уменьшении натяга $N$, вследствие истирания ворса, толщина покрытия упадет ниже 3,5 мкм, что отрицательно скажется на износостойкости обработанного изделия. При дальнейшем уменьшении толщины покрытия начнут образовываться несплошности и щетка выйдет из контакта с поверхностью детали. Такой вариант обработки не может обеспечить устойчивого качества получаемых изделий.

Рассмотрим вариант управления процессом на основе поддержания натяга на заданном уровне $(N=$ const $)$, показанный на рис.2.

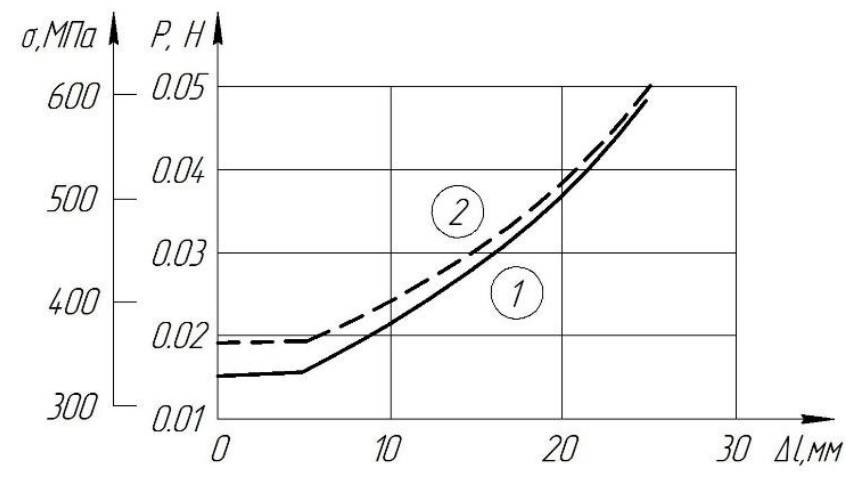

\section{Рисунок 2 - Зависимость: 1 - максимального напряжения, 2 - максимальной силы от величины истирания ворса.}

В данном случае, полученный график можно разбить на два участка. На начальном участке $(\Delta l=0 \div 5$ мм) сила и напряжения практически неизменны, а при истирании ворса уменьшается только радиус фиктивной заделки. Данный участок тем больше, чем меньше плотность набивки ворса. На практике применяются щетки с плотностью ворса от 0,05 до 0,2. При плотности набивки ворса близкой к максимальной данный участок имеет минимальные размеры или вовсе отсутствует. На конечном участке $(\Delta l>5$ мм) происходит уменьшение только изгибающейся части ворса, вызывая рост силы $P$ и напряжений $\sigma$, что приводит к появлению недопустимой разнотолщинности покрытия и нарушению условия выносливости:

$$
\sigma_{\max } \leq\left[\sigma_{r}\right]
$$

И как следствие, усталостному разрушению инструмента.

Введение адаптивной системы управления (АСУ) позволяет существенно уменьшить или свести на нет воздействие фактора истирания на качество получаемых покрытий и наиболее полно использовать срок службы гибкого инструмента.

Система поддерживает контактную силу на строго заданном уровне $(P=c o n s t)$ и позволяет в числе других возмущающих факторов (таких как естественный износ ворса, и т.д.), имеющих функциональную составляющую, компенсировать частично и температурные погрешности от нагрева детали в процессе обработки. Способ управления, основанный на энергосиловых параметрах процесса, связывает два важнейших технологических параметра - текущий натяг инструмента к обрабатываемой детали и затрачиваемую на процесс трения энергию, что дает возможность объединить преимущества, даваемые совместным использованием этих параметров [7] (рис.3). 


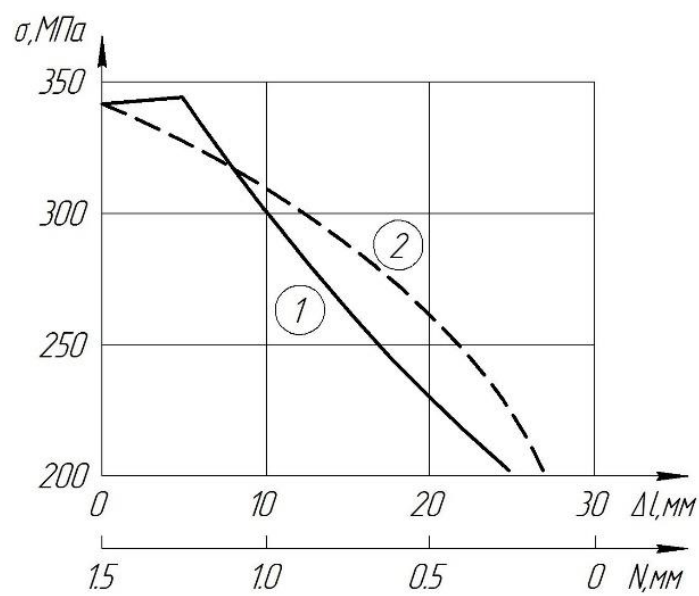

Рисунок 3 - Зависимость максимального напряжения при истирании от: 1 величины естественного износа ворса, 2 - натяга.

Представленные данные наглядно демонстрируют незначительный рост напряжений $\sigma$ на начальном участке, а на конечном участке их снижение. Однако, вместе с напряжениями уменьшается натяг $N$ и площадь плакирования $S$, что серьезно сказывается на производительности процесса. Судя по рис.3 управление процессом целесообразно до истирания ворса в районе 10 мм, после чего, без переналадки или замены инструмента, ввиду серьезного уменьшения изгибающейся части ворса, в нем начинают происходить другие, не рассматриваемые в данном анализе процессы.

На рис.4 представлены зависимости для ранее заданных параметров плакирования с шириной щетки $B=20$ мм.

Используя полученные зависимости (рис.4) появляется возможность рассчитать уменьшение продольной подачи в зависимости от износа гибкого инструмента для поддержания заданного качества обработки; используя переналаживаемую щетку, выбрать оптимальное время для переналадки или замены проволочного инструмента, обеспечивающее максимальную производительность процесса.

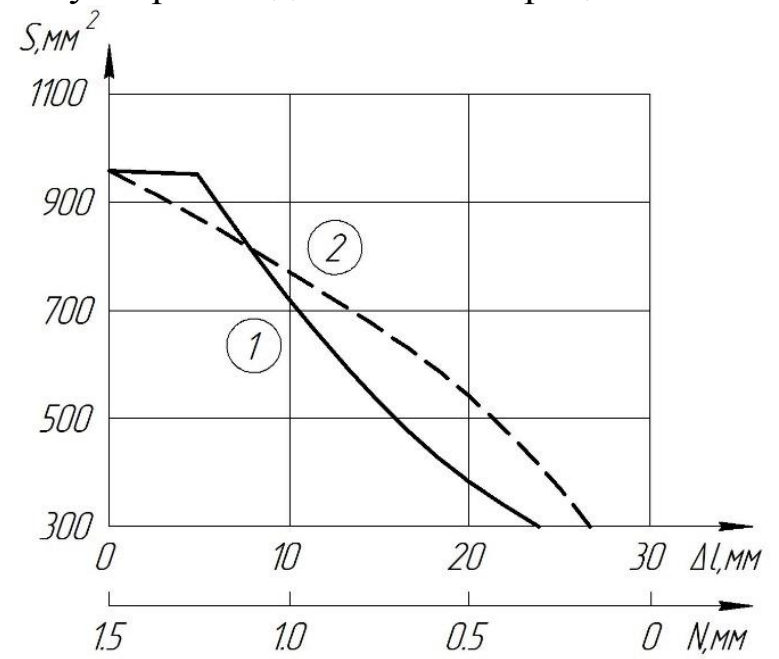

Рисунок 4 - Зависимость площади плакирования от: 1 - величины естественного износа ворса, 2 - натяга.

Таким образом, внедрение адаптивной системы управления, компенсирует влияние износа гибкого инструмента, динамические и температурные погрешности обработки, поддерживает контактную силу на необходимом уровне, и как следствие повышает качество обработки. По зависимости площади плакирования от величины 
естественного износа выбирается оптимальное время смены (переналадки) инструмента.

\section{Литература:}

1. Анцупов В.П., Завалищин А.Н., Кадошников В.И., Дема Р.Р. Повышение стойкости режущего инструмента нанесением композиционных антифрикционных покрытий // Технология машиностроения. 2003. № 4. С. 25-26.

2. Кадошников В.И., Анцупов В.П., Дема Р.Р., и др. Расширение технологических возможностей метода плакирования гибким инструментом. // Вестник машиностроения. 2003. № 10. С. 64-67.

3. Зотов А.В., Драчев О.И. Оценка износостойкости направляющих скольжения, подвергнутых плакированию // Металлообработка. 2013. № 3. С. 5-10.

4. Савельев В.Б., Анцупов В.П., Боков А.И. Номограмма для определения peсурса гибкого плакирующего инструмента // Моделирование и развитие технологических процессов обработки металлов давлением: сб. науч. тр. Магнитогорск: МГТУ им. Г.И. Носова. 1999. С. 183-189.

5. Zotov A.V.,Semenchenko N.V. Selecting a material for pile wire tool // Pressing issues and priorities in development of the scientific and technological complex: research articles, B\&M Publishing, San Francisco, California. 2013. Pp. 113-116.

6. Боков А.И. Повышение долговечности деталей металлургического оборудования методом плакирования гибким инструментом с учетом его износа и усталостного разрушения: диссертация кандидата технических наук. Магнитогорск 2001. 129 c.

7. Зотов А.В., Семенченко Н.В. Стабилизация энергосиловых параметров при плакировании гибким инструментом // Механики XXI веку. XII Всероссийская научнотехническая конференция с международным участием: сборник докладов. - Братск: Изд-во БрГУ, 2013. - С. 126-128. 